\title{
EMPOWERMENT IN THE PUBLIC SECTOR: TESTING THE INFLUENCE OF GOAL ORIENTATION
}

\section{INTRODUCTION}

Empowerment is a key element within New Public Management (NPM) (Fernandez and Moldogaziev 2013), the new orientation in the public sector that aims to provide a better service for citizens (Nicholson-Crotty, Nicholson-Crotty, and Fernandez 2016). In many countries, the public sector has undergone reforms attempting to change the structure, way of management, and even the culture of public administration (Üstuner and Coşkun 2004; Worthington and Dollery 2001), as well as the management of people (Truss 2013). Peters and Savoie (1996) describe how the current form of government proposes more decentralized organizations and more empowered employees at all levels of the hierarchy. Thus, empowerment has reemerged as a component of significant government reforms around the world (Brewer and Kellough 2016). It is closely linked to the drive to enhance organizational effectiveness through the wise use of human resources (Siegall and Gardner 2000, 703), and in this sense, many studies have found positive effects of implementing empowerment (see e.g., Maynard, Gilson, and Mathieu 2012). Overall, as Dimitriades $(2005,80)$ notes, it "is essential to the constant change and learning that characterize today's global organizational environment."

Nevertheless, and despite the numerous studies on the subject and the importance attributed to empowerment, it "is a tricky concept to grasp" (Matthews, Diaz, and Coles 2003, 315), and no single definition has been agreed on (Petter et al. 2002). Empowerment has therefore been examined from several separate perspectives (Chen and Chen 2008; Dimitriades and Maroudas 2007; Mathieu, Gilson, and Ruddy 2006), although two main approaches can be distinguished: structural and psychological. The structural perspective views empowerment as a set of practices, conditions, policies and structures that enable the transfer of power and 
authority from higher levels of the organization to lower levels, increasing access to information and resources (Bowen and Lawler 1992; Mathieu, Gilson, and Ruddy 2006). It is "a managerialinitiated, socio-structural phenomenon" (Biron and Bamberger, 2010, 164); hence, it refers to empowering managerial practices. Overall, it constitutes the 'macro' approach to empowerment (Biron and Bamberger 2010). The psychological perspective, in contrast, is based on Bandura's (1977) work on self-efficacy (Maynard, Gilson, and Mathieu 2012), and defines empowerment as "a process of enhancing feelings of self-efficacy among organizational members through the identification of conditions that foster powerlessness and through their removal by both formal organizational practices and informal techniques of providing efficacy information" (Conger and Kanungo 1988, 474). Following this idea, Thomas and Velthouse $(1990,666)$ describe empowerment "as increased intrinsic task motivation." This perspective considers the individual employee level, representing the 'micro' approach to empowerment (Biron and Bamberger 2010),

Many authors (e.g., Laschinger, Finegan, and Shamian 2001; Mathieu, Gilson, and Ruddy 2006; Maynard, Gilson, and Mathieu 2012; Menon 2001) argue that these two perspectives must be linked to arrive at a broader understanding of the empowerment process. The few recent studies that have dealt with this issue have positioned structural empowerment practices as antecedents of psychological empowerment (e.g., Hempel, Zhang, and Han 2012; Seibert, Silver, and Randolph 2004). However, public sector scholars have paid little attention to the study of empowerment in general, calling for more studies in this field (Carless 2004), and pointing to the lack of research on the relationship between structural and psychological empowerment (Cho and Faerman 2010). Empirical contributions on this relationship are therefore important, particularly as empowerment is a very useful tool with which to face the challenges of the new public context. As Cho and Faerman (2010) note, to benefit from the 
effectiveness of the new techniques, leaders in government organizations should pay attention to both structural and psychological empowerment.

Furthermore, there is also a need to examine how structural empowerment can interact with other variables to achieve psychological empowerment (Maynard, Gilson, and Mathieu 2012). The literature review shows that the effect of moderator variables in this relationship has so far been neglected. In this vein, Maynard, Gilson, and Mathieu (2012) propose the study of the effect of individual orientations, such as goal orientation (GO) (e.g., Dweck 1986). VandeWalle $(1997,995)$ understands the concept of GO as "an individual disposition toward developing or validating one's ability in achievement settings." It is, therefore, a personality variable and an individual difference (VandeWalle et al. 1999). Drawing from this view, we focus on the study of employees' GO as a moderating variable in the structural and psychological empowerment relationship. Employees' GO may be a key factor at work and in workforce selection processes, since it explains the differences in personal work interests and behaviors, and in receptiveness to and interpretations of professional development activities (Joo, Park, and Lim 2016; VandeWalle 1997). Structural empowerment practices could therefore affect psychological empowerment feelings in very different ways, depending on employees' GO, since they perceive and respond differently to such practices, which is likely to yield different psychological empowerment results.

The objective of this study is to conceptually develop and empirically test a model proposing that structural empowerment is related to psychological empowerment in employees, and that this link is different depending on their goal orientations. Our study responds to Petter et al.'s (2002) call for more academic attention to how public organizations influence their employees, providing more successful and integral research on empowerment, and to Maynard, Gilson, and Mathieu's (2012) call for research on the moderator factors that may influence the structural and psychological empowerment relationship. The study makes two main 
contributions to the literature. Firstly, by examining the structural-psychological empowerment relationship we extend the scant empowerment literature in public management. Since structural empowerment has largely been emphasized as an administrative strategy to increase work-related outcomes, rarely considering the psychological empowerment approach (Cho and Faerman 2010), evidence on psychological empowerment in public organizations is scarce (Dimitriades and Maroudas 2007). Furthermore, research on the structural-psychological empowerment link in the public sector has mainly looked at the field of health, particularly nursing (Laschinger, Finegan, and Shamian 2001; Laschinger et al. 2004). Cho and Faerman (2010) carried out one of the few studies on the structural and psychological empowerment relationship in the public sector (other than the health services), finding that structural empowerment affects extra-role performance through psychological empowerment in a sample of public employees working in the city of Seoul (Korea). Therefore, our work aims to provide new empirical evidence about empowerment in the public sector by addressing the link between its two approaches in the local authority context. In doing so, we follow Bowen and Lawler's (1992, 1995) structural empowerment conceptualization and Spreitzer's conceptualization of psychological empowerment, and relate them to the public administration framework.

Secondly, we examine the moderating effects of employees' GO levels in this relationship. We aim to add to the empowerment literature by extending the limited understanding of possible moderator variables. Furthermore, to the best of our knowledge, public administration research has not examined the GO concept, leaving a significant research gap. Likewise, more generally, only one empirical study (Joo, Park, and Lim 2016) has dealt with the influence of GO on psychological empowerment, although it focuses on only one of its dimensions (learning goal orientation). Given that public sector human resources are the main input in delivering services, examining people's motivations to achieve in their work 
context is an issue of great interest, and in this study we respond to the need to consider motivational aspects in the public sector (Perry 2010; Vandenabeele et al. 2005). Local governments are a permanent workplace for many employees (Barba and Serrano 2015), and are the level of government closest to citizens. Therefore, employees' GO, and its interaction with structural empowerment practices emanating from new managerial techniques and legal rules (NPM, EBEP 2007, Estatuto Básico del Empleado Público, in English, the Basic Statute of the Public Employee), as well as its corresponding effects on employees' psychological state (here, psychological empowerment), are important issues to examine. To address this, we review arguments from GO theories, and previous related contributions.

In light of the above, we consider that the present study can shed more light on the question of empowerment in the public administration, local governments in this case, and can also help to bridge the gap in the literature on the moderating variables in empowerment research and the motivational issue in the public sector. The rest of paper is organized as follows: the next section provides a review of the literature on empowerment, GO, and the public context, and presents the study hypotheses. The data and methods used are then explained, followed by the results of the analysis. Finally, we present the discussion, with the study's implications, limitations, and conclusions.

\section{THEORETICAL FRAMEWORK}

We consider Bowen and Lawler's vision of empowerment as the most suitable for the current study, following previous contributions (e.g., Fernandez and Moldogaziev 2011, 2013, 2015) that have also dealt with empowerment in the public sector. As Fernandez and Moldogaziev (2011) state, Bowen and Lawler $(1992,1995)$ developed the most widely known definition of structural empowerment, analyzing the use of empowerment practices in private service firms, and defining it as the "approach to service delivery" (Bowen and Lawler 1992, 32). According 
to Bowen and Lawler $(1992,1995)$, sharing power and authority with frontline employees is a key element of an empowering approach to management, but it is not sufficient to achieve the benefits of (structural) empowerment. These authors identify four practices that need to be considered to achieve a notable effect on performance: (1) sharing power to make decisions, (2) redistributing information about the organization's performance, (3) providing knowledge that enables employees to understand and contribute to organizational performance, and (4) offering rewards based on the organization's performance (1992, 32). Empowerment exists when all these practices are in place.

Spreitzer's (1995) concept of psychological empowerment has received a great deal of international recognition and is followed by the majority of authors. Following Thomas and Velthouse (1990), Spreitzer (1995, 1444) describes psychological empowerment "as a motivational construct manifested in four cognitions: meaning, competence, selfdetermination, and impact." Meaning is the judgment of the fit between the ideals and standards of the employee and his or her work goal or purpose. The second factor, competence, is the individual's belief in his or her capability to carry out work tasks with skill. Third, selfdetermination or autonomy is related to the feeling that one is able and allowed to initiate and continue work actions. Finally, impact is the degree to which individuals feel they can influence outcomes at work (Spreitzer 1995; Thomas and Velthouse 1990).

Regarding our context of study, the components or dimensions of psychological empowerment (meaning, competence, self-determination, and impact) are essential factors in local government human resources management, and help employees to face the challenges of the new public management environment. For public employees, feelings of empowerment are highly relevant to their work routine, since they usually want to serve the public interest, and are more motivated by the intrinsic compensation they receive from accomplishing tasks (Houston 2000). Optimal service is determined by employees feeling they exercise control over 
how they work to achieve their job objectives (Cuenca 2010). This helps them to perceive that the activities and tasks that they carry out have an effect on the general results (Taylor 2013). Additionally, the modern local government context implies that employees must feel that they are making decisions and developing activities autonomously, in direct contrast to concentrated levels of authority (Vandenabeele et al. 2005).

\section{Structural and Psychological Empowerment Link}

Within the empowerment framework, research initially focused on structural empowerment (e.g., Block 1990; Bowen and Lawler 1992), analyzing issues such as distribution of power and decision making, training or planning and control systems. The emphasis then shifted to the psychological state of empowerment, but neglected the structures and practices that actually stimulate empowerment (Hempel, Zhang, and Han 2012). Wisely, some researchers (e.g., Menon 2001) have highlighted the need to examine both types of empowerment in combination.

Thomas and Velthouse's (1990) vision of empowerment in the workplace (which spawned Spreitzer's definition of psychological empowerment) held that psychological empowerment is influenced by the work environment, and therefore empowerment practices (structural empowerment) help employees to develop and create an active and optimistic orientation to their job and to feel that they can carry out their work activities appropriately. Therefore, empowering practices create an empowered state of mind in employees that includes control over what happens on the job, autonomy in doing the job and acting naturally with customers, and consciousness of the work environment, among others (Bowen and Lawler 1995). All these feelings are closely related to Spreitzer's psychological empowerment dimensions.

Later studies combining the two empowerment approaches (e.g., Hempel, Zhang, and Han 2012; Laschinger et al. 2004; Seibert, Silver, and Randolph 2004) positioned structural 
empowerment as a necessary antecedent to psychological empowerment (Maynard, Gilson, and Mathieu 2012). One of the first researchers to propose this link was Spreitzer $(1995,1996)$, who found that low role ambiguity, sociopolitical support, access to information, and participative climate generate potential for (psychological) empowerment in the workplace. Other authors who have studied this relationship in a wide variety of service firms (Wallace et al. 2011) affirm that empowering practices such as autonomy, reward system, and participative decision making have beneficial effects on the psychological empowerment level of the employees.

Despite its importance and the empirical evidence found, empowerment, especially psychological empowerment, has rarely been studied in the public sector context (Dimitriades and Maroudas 2007; Cho and Faerman 2010). Cho and Faerman (2010) conducted one of the few studies examining the structural and psychological empowerment link in an area of the public sector other than health services. Using a sample of public employees from the city of Seoul (Korea), they found that structural empowerment (participative decision making, delegation and feedback) affects extra-role performance through psychological empowerment. Self-determination theory (Deci and Ryan 1980; Deci et al. 2001) can provide theoretical support for such linkages. This theory holds that everybody has three basic psychological needs: competence, autonomy, and relatedness. Employees will feel psychological well-being and motivation when they perceive these needs are satisfied in their organizations. Structural empowerment provides employees with possibilities to enhance their abilities and knowledge through training and information programs, to make decisions on organizational and job matters, and to relate to their peers by allowing them to become involved in decision-making programs. Thus, structural empowerment interventions would help to meet employees' basic needs, enhancing their intrinsic motivation and well-being, and therefore, their feelings of psychological empowerment. 
Keeping in mind the above, it is clear that elements of structural empowerment, such as sharing information or granting decision-making power, are key ways to boost employees' feelings of psychological empowerment. Although most studies on the link between structural and psychological empowerment have focused on health service organizations, or other service sector firms, in light of the studies reviewed, the legislative tendencies, and the local administration context, structural empowerment is likely to be valuable and have considerable repercussions on the psychological empowerment of local government employees. Therefore, we propose that:

Hypothesis 1. There is a positive relationship between structural empowerment and psychological empowerment.

\section{Employees' goal orientation}

GO is a motivational concept (Deshon and Gillespie 2005; Cellar et al. 2011; Lee, Tinsley, and Bobko 2003) as it impacts the employee's level of motivation (Button, Mathiew, and Zajac 1996; Spinath and Steinmayr 2012). The growing research on motivation in public sector organizations (Vandenabeele 2013) shows similarities (e.g., Buelens and Van den Broeck 2007) as well as differences (e.g., Houston 2000) between public and private employees. Some types of goals have been studied in the public sector, such as goal content or goal commitment (e.g., Wright 2001; Wright 2007). However, as Wright (2001) states, there is still a lack of attention to work motivation in the public sector, and a better understanding of this question is crucial to improve the efficiency and effectiveness of public organizations. After all, human resources make the difference, and their motivation, and therefore their GO, should be regarded as essential to public sector organizations (Vandenabeele 2013). 
There is a certain consensus about taking a three-dimensional approach to the conceptualization of GO (e.g., Brett and VandeWalle 1999; Elliot and Church 1997; VandeWalle 1997), which has been most commonly used in recent years (Phan 2009). This conceptualization of GO comprises the following three factors:

- $\quad$ Learning Goal Orientation (LGO): directed to increase competence by acquiring new skills and mastering new circumstances (Dweck 1986), and involves rising to challenges and learning in a certain performance area (Chen et al. 2000).

- $\quad$ Prove-Performance Goal Orientation (PPGO): desire to demonstrate one's own aptitude and to be positively judged on it (VandeWalle 1997), with an intrinsic enthusiasm to compete against others (Dietz et al. 2015).

- $\quad$ Avoid-Performance Goal Orientation (APGO): desire to avoid disapproval of one's capability and undesirable judgments on it (VandeWalle 1997); characterized by avoidance of inadequate performance and its negative results (Martin, Marsh, and Debus 2001).

\section{The Moderating Role of Goal Orientation on the Relationship between Structural Empowerment and Psychological Empowerment}

GO theory (Dweck 1975; Pintrich 2000; VandeWalle 1997) strives to determine what leads people to respond differently to achievement settings (Rusk and Rothbaum 2010). It can therefore be useful to explain the impact of the GO dimensions on the structural-psychological empowerment link within the public administration framework. As VandeWalle (1997) states, every employee is different, and differences in their work interests and actions are therefore to be expected. The explanation for these differences has to do with goal orientations (VandeWalle 1997). In line with this argument, we analyze the different kinds of goal orientations and their moderating power. 
Individuals with high LGO are inclined to think that their capabilities are malleable and can be extended (Brett and Atwater 2001). Thus, people with high LGO approach tasks with the aim of developing their capabilities (Lee, Tinsley, and Bobko 2003), and take pains to understand new information (Wolters 2003). It makes sense, therefore, to assume that LGO will be positively associated with willingness to take part in training activities (Button, Mathieu, and Zajac 1996), as these individuals believe their ability is malleable and can be improved (Brett and VandeWalle 1999). This idea is also supported by Towler and Dipboye (2001), whose empirical study showed that LGO positively moderates the effects of training: the high learning goal oriented trainees were more motivated to learn and responded more positively to the trainer and the lecture. Likewise, as individuals with strong LGO are more motivated to use learning processes when facing problems and obstacles, they develop expertise more easily and create strategies to become successful (Gong, Huang, Farh 2009), which can strengthen the effects of structural empowerment interventions on, for instance, their feelings of competence and impact. Furthermore, people with this goal orientation perceive negative feedback as valuable information on how to develop mastery (Dweck 1986), and perform better in challenging tasks, as demonstrated by Preenen, Van Vianen, and Pater (2014), who found a positive relationship between employees' mastery-approach orientation and performance of challenging tasks on a sample of workers. According to Coad's (1999) study in an accounting environment, accountants with LGO are more likely to become involved in the management decision process. Therefore, it is plausible that in the context of structural empowerment implementation employees with high LGO will experience higher levels of psychological empowerment. Structural empowerment interventions will have a higher positive association with the development and enhancement of employees' psychological empowerment because they provide empowerment practices designed to increase employees' feelings of control over their work and over their skills to perform activities, which can be more easily achieved when 
employees are willing to be trained, to learn, to improve their skills, to meet challenges, and to become familiar with new information. In the specific context of NPM, in which public employees have to learn and master new demands and tasks in order to provide better services, their levels of LGO combined with structural empowerment practices could play a pivotal role in their feelings of empowerment. Thus, the review of the literature suggests that the higher the level of LGO, the stronger and more positive the link between structural empowerment practices and psychological empowerment will be.

The empirical evidence related to PPGO is inconclusive (Midgley, Kaplan, and Middleton 2001) due to mixed findings (e.g., Elliot and Moller 2003; Payne, Youngcourt, and Beaubien 2007) depending on whether the more traditional or the revised perspective of GO is considered. The more traditional perspective (e.g., Ames 1992) holds that any concern with performance could have detrimental effects on participation in a task due to the distraction brought about by comparisons with others or negative self-evaluation (Pintrich 2000). However, according to the most recent perspective, the revised goal theory (Pintrich 2000), performance goals may be a useful tool since they offer an external orientation with which to assess performance, and they are a guide for understanding feedback (Butler and Winne 1995).

Drawing on this latest perspective, and given that individuals with high PPGO attempt to show their ability by trying to appear better than others (Brett and VandeWalle 1999), we assume that they will see opportunities to demonstrate their ability when they are given the chance to take decisions by themselves, are rewarded for their productivity, or receive training, thus enhancing the effects of structural empowerment on psychological empowerment. Therefore, and from the limited literature on this issue (Joo and Park 2010), which postulates a more adaptive role for prove performance goals (Pintrich 2000), we consider that the higher the level of PPGO, the more likely structural empowerment practices (e.g., knowledge and training, power to make decision) are to have a positive relationship with psychological empowerment. 
The latest reforms in the public sphere have attempted to improve human resource management and to use public resources more efficiently by implementing methods such as performance appraisal (Barba and Serrano 2015). High-PPGO employees' levels of psychological empowerment could rise in this new situation, in which their individual performance and comparison with other workmates is revealed, an aspect they pursue and enjoy.

Finally, research on APGO has uncovered its relationship with maladaptive patterns and responses (Chadwick and Raver 2015; Pintrich 2000). As individuals with this goal orientation seek to avoid criticism of their competences and negative judgments from others (VandeWalle 1997), we expect that structural empowerment practices, such as delegating decision-making power, will have a lower association with psychological empowerment levels when APGO is high. The reason for this assumption is that these individuals feel threatened by the achievement context (Elliot and Harackiewicz 1996), and we consider that the possibility of taking decisions by themselves, being rewarded for their performance, or participating in training activities can be interpreted as a threat, due to fear of failure (Spinath and Steinmayr 2012). In addition, APGO triggers a process that complicates ideal task engagement (Elliot and Harackiewicz 1996). Hence, feelings of psychological empowerment derived from structural empowerment interventions are likely to be lower among individuals with high APGO, since mechanisms related to APGO may erode the positive effects of practices such as training, information, rewards or decision making. Moreover, this goal orientation predicts selfhandicapping (Midgley and Urdan 2001), so the lower the degree of avoid-performance goal orientation, the stronger and more positive the association of structural empowerment practices, such as knowledge and training, and decision-making power, with psychological empowerment. In contrast, the self-handicapping feelings derived from high APGO will hamper the emergence of positive feelings of empowerment, since high-APGO individuals will perceive that they cannot face structural empowerment practices that entail carrying out new 
activities and meeting new challenges, such as training in new fields or suggesting ideas for the work routine. For high-APGO public employees, the possibility of failure after a performance appraisal could reduce feelings of psychological empowerment.

Thus, from the findings of previous contributions and the theoretical arguments exposed above, we put forward the following hypotheses:

Hypothesis 2a. LGO positively moderates the relationship between structural empowerment and psychological empowerment.

Hypothesis 2b. PPGO positively moderates the relationship between structural empowerment and psychological empowerment.

Hypothesis 2c. APGO negatively moderates the relationship between structural empowerment and psychological empowerment.

Our conceptual model is represented in figure 1.

Figure 1 Theoretical model

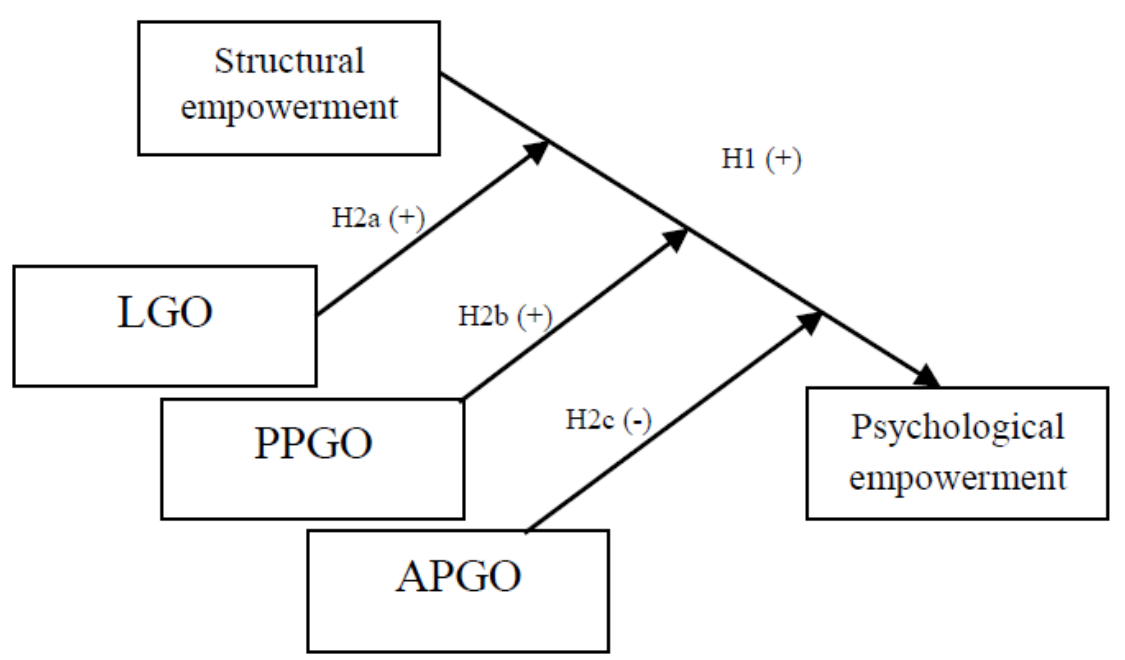




\section{METHOD}

\section{Sample and Data Collection}

In the context of Spain's new legal rules (EBEP 2007), Spanish local authorities were considered as a suitable frame to test the relationship between the two empowerment approaches. Spanish local governments have undergone significant modifications in recent years (Suárez and Ysa 2011). The EBEP aims to enhance participation and improve human resource management through principles and actions related to structural empowerment (e.g., training, performance-related bonuses and the importance of producing understandable and meaningful structures for local government employees (Cuenca 2010) that also promote their psychological empowerment. Citizens today receive highly professional and diverse services (Vermeeren, Kuipers, and Steijn 2011), which reflects the importance of the human factor in current administrative institutions (Giménez and Prior 2007; Kim and Wright 2007).

The fieldwork for this study took place in Spanish municipalities of more than 20,000 inhabitants. We focused on large municipalities as they implement more strategic management techniques (Poister and Streib 2005), including structural empowerment techniques (Seibert, Wang, and Courtright 2011). Following previous contributions (e.g., Barba and Serrano 2015; Rosa, Morote, and Colomina 2013) we used the number of inhabitants as an index, which yielded a population of 399 municipalities taken from the Federación Española de Municipios y Provincias (FEMP, Spanish federation of municipalities and provinces) database.

Two surveys were prepared: one for local government managers (e.g., human resource manager, clerk), and a second for other public workers. Collecting data from two different sources limits problems associated with common method variance (Collins and Smith 2006; Gardner, Wright, and Moynihan 2011). The questionnaires were then uploaded onto an internet survey application and pretested with four local government managers and other employees to assess and improve the measures. Improvements were then made to the questionnaires in 
accordance with the outcomes of the pretest. The data collection procedure involved first telephoning the city councils and identifying the human resource managers or the person in charge of personnel management (sometimes the clerk or the auditor) to describe the study and request their email addresses. Emails containing links to the two surveys were sent to these managers. They were asked to respond to the managers' questionnaire and were invited to email the employees' questionnaire at random to a minimum of three employees. A follow-up telephone call was made to increase the response rate, as recommended in the literature (Dillman, Smyth, and Christian 2009).

We removed city councils with fewer than 3 employee responses, which resulted in a sample of 109 manager questionnaires and 521 employee questionnaires, representing $27.32 \%$ of the total population. The sample error for the local governments sample was \pm 8.09 at $5 \%$ significance level. In addition, the presence of non-response bias was examined by testing for differences between responses that were included in the study (local governments with responses from both managers and employees) and responses from local governments not included because not all the required questionnaires were completed (e.g., only one employee filled in the questionnaire) (Whitehead, Groothuis, and Blomquist 1993) through a $t$-test on the scores. No significant differences $(p<.05)$ were found in any of the main or control variables; no evidence of non-response bias was therefore detected in the study. The average number of employees (excluding the human resource manager) participating in each city council was 4.78 . The respondents surveyed belonged to a wide range of local authority administrative services, including human resource management, social services, accounting, tourism, and town planning. The majority of the participants were women (62.2\%), and non-supervisors $(67.4 \%)$. Their average age was 46.71 years $(S D=7.58)$, and they reported an average tenure in their organization of 17.25 years $(S D=9.56)$. 


\section{Measures}

The appendix provides a complete description of the instruments used in our study. The scales were constructed originally in English. As recommended (e.g., Ghauri, Kristianslund, and Gronhaug 1995), we followed standard translation and back-translation procedures to translate the measures into Spanish,

Structural empowerment was measured using twenty-two items adapted from Lawler, Mohrman, and Benson's (2001) scale. Local authority managers responded to items on the four dimensions - decision-making power, information sharing, rewards, and knowledge and training - on a 7-point scale ranging from 1 (no employees) to 7 (all employees). Following previous studies (e.g., Datta, Guthrie, and Wright 2005), a single indicator was calculated by taking the mean of the four subscales generated from the questionnaire items. The internal reliability coefficient (Cronbach's alpha) for this composite measure was 0.93 .

We used Spreitzer's (1995) Psychological Empowerment Scale to measure psychological empowerment; this is the most widely used scale in the literature. It consists of four subscales, one for each dimension of empowerment (meaning, competence, selfdetermination and impact). The twelve items are answered on a 7-point Likert-type scale ranging from 1 (strongly disagree) to 7 (strongly agree). The employees' responses were averaged to create an overall psychological empowerment index following previous literature (e.g., Seibert, Silver, and Randolph 2004; Taylor 2013). Taken together, the items showed high reliability $(\alpha=0.86)$.

To measure Goal Orientation, we used Brett and VandeWalle's (1999) 13-item scale, which is specific to work settings. It assesses the levels of LGO $(\alpha=0.84)$, PPGO $(\alpha=0.91)$, and APGO ( $\alpha=0.81)$ of employees on a 7-point Likert-type scale ranging from 1 (strongly disagree) to 7 (strongly agree). Ratings on items for each subscale were averaged to build scores for LGO, PPGO, and APGO, guided by previous studies (e.g., VandeWalle 2001). 
Finally, in line with previous literature (e.g., Jong and Ford 2016), we controlled for tenure in the organization (years working in the city council), gender (male $=0$ or female $=1$ ), job position (supervisor $=1$ or non-supervisor $=0$ ), age (years), size of the local government (log-transformed number of employees), given that large municipalities put into practice more strategic management techniques (Poister and Streib 2005), and the strategic integration of HRM in the overall local authority strategy. This final aspect was measured by asking whether the human resource manager or the person in charge of human resource issues participates in city council meetings in which important questions are debated (yes $=1 ;$ no=0). The rationale behind the inclusion of this variable is that the strategic importance of the human resource question in an organization can affect its results (e.g., Huang 2000).

\section{RESULTS}

\section{Tests of the Measurement Model}

Confirmatory factor analyses (CFA) for each scale were conducted to examine the dimensionality of goal orientations (LGO, PPGO, and APGO), psychological empowerment, and structural empowerment. First, a CFA was performed to assess the fit of a four-factor model for the 12 items of psychological empowerment, providing a good fit $\left(\mathrm{S}-\mathrm{B} \chi^{2}=107.6541, \mathrm{df}=48\right.$; BBNNFI=0.969; $\mathrm{CFI}=0.977 ; \mathrm{RMSEA}=0.049)$. Then, a second-order factor $\mathrm{CFA}$ was estimated in which the first-order constructs of meaning, competence, self-determination, and impact were each loaded onto a single second-order latent construct representing psychological empowerment. The higher-order model also demonstrated an adequate fit to the data (S$\mathrm{B} \chi^{2}=140.2558, \mathrm{df}=50 ; \mathrm{BBNNFI}=0.955 ; \mathrm{CFI}=0.966$; $\left.\mathrm{RMSEA}=0.059\right)$, so the model supports the higher-order factor structure of psychological empowerment. Regarding GO, a CFA of the 13 items loading onto their corresponding factors (LGO, PPGO and APGO) indicated a good fit to the data for the three-factor model $\left(\mathrm{S}-\mathrm{B} \chi^{2}=208.0820, \mathrm{df}=62 ; \mathrm{BBNNFI}=0.900 ; \mathrm{CFI}=0.919\right.$; 
RMSEA=0.067), thereby supporting past findings (e.g., Brett and VandeWalle 1999; VandeWalle et al. 2001). Finally, the confirmatory factor analysis results showed an adequate fit of a four-factor model for the 22 items of structural empowerment $\left(\mathrm{S}-\mathrm{B} \chi^{2}=283.7685, \mathrm{df}=195\right.$; BBNNFI=0.900; CFI=0.901; RMSEA=0.065). The good fit of a single second-order latent construct representing structural empowerment was also confirmed $\left(\mathrm{S}-\mathrm{B} \chi^{2}=286.2015, \mathrm{df}=197\right.$; $\mathrm{BBNNFI}=0.900 ; \mathrm{CFI}=0.900 ; \mathrm{RMSEA}=0.065)$.

\section{Descriptive Statistics and Correlation Analysis}

Table 1 shows means, standard deviations, and correlation coefficients for the study variables. Contrary to expectations, structural empowerment and psychological empowerment are not correlated. Regarding goal orientation, both LGO and PPGO are positive and significantly correlated with psychological empowerment $(r=0.41, p<.01$, and $r=0.23, p<.01$, respectively), but no significant link is found between psychological empowerment and APGO. Table 1 - Means, Standard Deviations, and Correlation Coefficients

\begin{tabular}{|c|c|c|c|c|c|c|c|c|c|c|c|c|c|}
\hline Variable & Mean & SD & 1 & 2 & 3 & 4 & 5 & 6 & 7 & 8 & 9 & 10 & 11 \\
\hline $\begin{array}{l}\text { 1. Structural } \\
\text { empowerment }\end{array}$ & 2.55 & 0.85 & 1.00 & & & & & & & & & & \\
\hline 2. & & & & & & & & & & & & & \\
\hline $\begin{array}{l}\text { Psychological } \\
\text { empowerment }\end{array}$ & 5.43 & 0.82 & -0.01 & 1.00 & & & & & & & & & \\
\hline 3. LGO & 5.90 & 0.84 & -0.02 & $0.41 * * *$ & 1.00 & & & & & & & & \\
\hline 4. PPGO & 3.85 & 1.50 & 0.05 & $0.23 * * *$ & $0.20 * * *$ & 1.00 & & & & & & & \\
\hline 5. APGO & 2.81 & 1.36 & -0.01 & 0.08 & $-0.13 * * *$ & $0.40 * * *$ & 1.00 & & & & & & \\
\hline 6. Tenure & 17.25 & 9.56 & -0.04 & $0.12 * * *$ & $-0.12 * * *$ & $-0.11 * *$ & -0.01 & 1.00 & & & & & \\
\hline 7. Age & 46.71 & 7.58 & 0.01 & $0.16 * * *$ & -0.03 & -0.06 & 0.02 & $0.70 * * *$ & 1.00 & & & & \\
\hline 8. Job position & 0.33 & 0.47 & 0.03 & $0.35 * * *$ & 0.08 & 0.04 & 0.07 & $0.23 * * *$ & $0.22 * * *$ & 1.00 & & & \\
\hline 9. Gender & 0.62 & 0.49 & 0.02 & $-0.10 * *$ & 0.02 & -0.01 & -0.03 & -0.08 & $-0.09 * *$ & $-0.15 * * *$ & 1.00 & & \\
\hline 10 & & & & & & & & & & & & & \\
\hline $\begin{array}{l}\text { Organization } \\
\text { size }\end{array}$ & 489.83 & 780.88 & 0.02 & -0.05 & 0.01 & 0.01 & -0.06 & $0.09 * *$ & $0.11 * *$ & -0.05 & $0.11 * *$ & 1.00 & \\
\hline 11. Strategic & & & & & & & & & & & & & \\
\hline $\begin{array}{l}\text { integration of } \\
\text { HRM }\end{array}$ & 0.52 & 0.50 & $0.37 * * *$ & 0.00 & -0.04 & 0.03 & -0.02 & 0.01 & 0.03 & -0.03 & 0.03 & -0.01 & 1.00 \\
\hline
\end{tabular}




\section{Tests of Research Hypotheses}

Hierarchical regression analysis was conducted to test the research hypotheses using SPSS 22 computer software. As recommended in the literature (Aiken and West 1991), we centered the variables to perform the analysis of the interaction between structural empowerment, LGO, PPGO, and APGO. Table 2 shows the results of the hierarchical regression procedure, first introducing the main effects and the second order interaction effects since a third order interaction is posited. To verify that Ordinary Least Squares (OLS) was the appropriate estimator to perform the analyses and avoid possible problems of model fit or misspecification, we tested the conditions of the Gauss-Markov Theorem (Wooldridge 2010). Thus, linearity in parameters and the normality of data was confirmed; random sampling was the method used to collect data; VIF (Variance Inflation Factor) values were below 2.5 in all the variables (control and main variables), showing no perfect collinearity; the Durbin-Watson statistic was 2.07, showing the independence of the error terms; and, finally, we assumed equality of variances given the absence of any pattern in the scatterplot of the estimates (values predicted by the model) plotted against the standardized residuals. These results allowed us to infer that OLS represented the best linear unbiased estimator (BLUE) (Wooldridge 2010).

Hypothesis 1 proposed a positive direct link between structural empowerment and psychological empowerment. Contrary to our expectations, as displayed in table 2, this link was not confirmed, since the regression coefficients are not significant for either Model 2 or for the full Model 3. Hypotheses 2a, 2b, and 2c proposed that the levels of LGO, PPGO, and APGO of local authority employees, respectively, moderate the effects of structural empowerment of psychological empowerment. As shown in Model 3 of table 2, only Hypothesis 2a is confirmed, since the interaction effect of structural empowerment and LGO was significant and positive $(\beta$ $=0.12, t=3.10, p<.01)$. 
Table 2 - Results of the hierarchical regression analysis

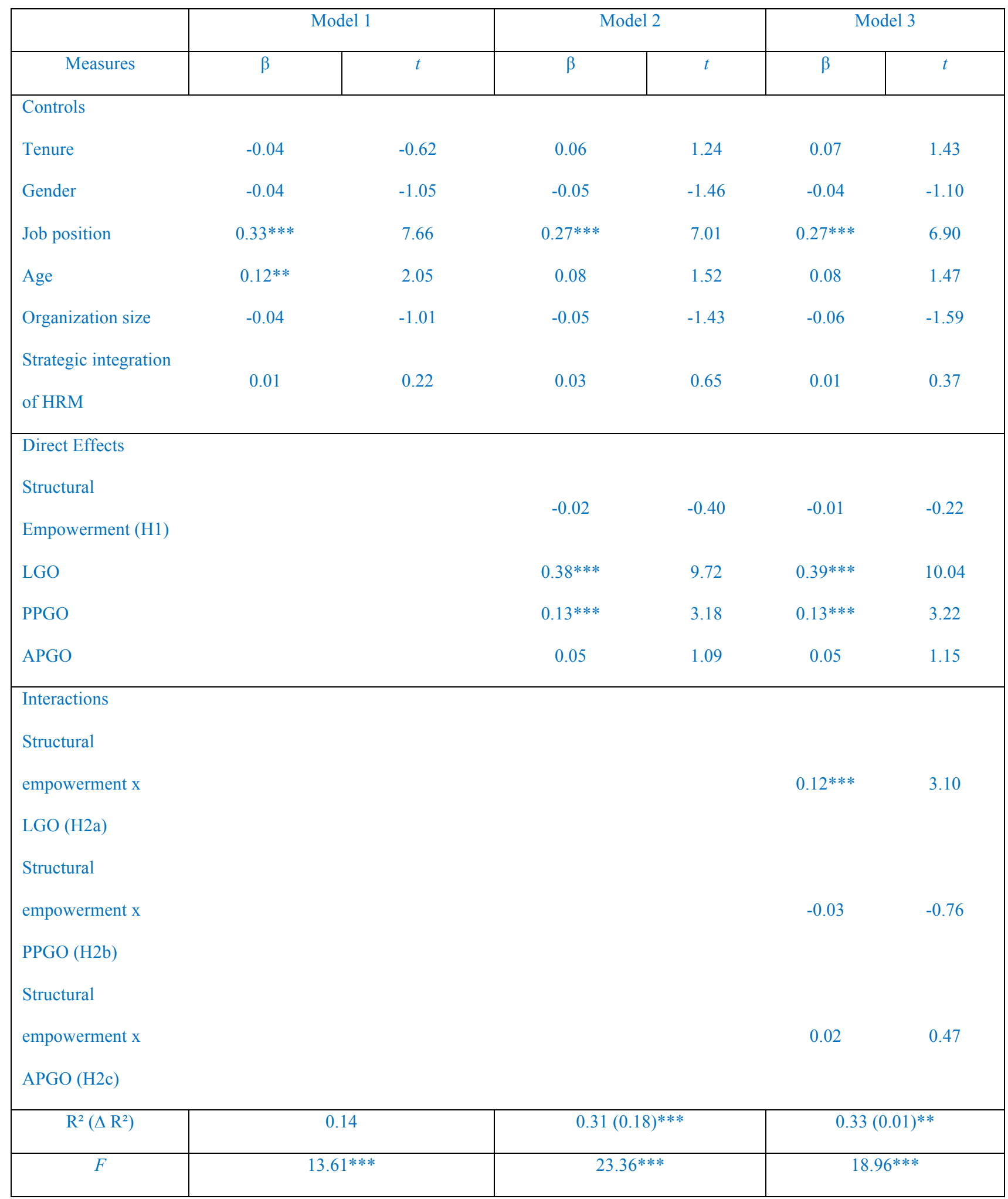

Note: ${ }^{* * *} p<.01, * * p<.05,{ }^{*} p<.10 ; N=521$. 
In order to better interpret the above results, Aiken and West (1991) recommend calculating and graphically representing the simple regression line of the principal variable (here, structural empowerment) on the dependent variable (here, psychological empowerment), according to the moderator (here, LGO). To do so, LGO was dichotomized based on the standard deviation above (high) and below (low) its mean value. The graphic representation (Figure 2) shows the psychological empowerment values calculated from the higher and lower values of structural empowerment, defined respectively by a standard deviation above (0.85) and below (-0.85) its mean value. Thus, a comparative analysis was made between two scenarios: high LGO and low LGO. Note that when the levels of LGO are high, the link between structural empowerment and psychological empowerment is positive and significant $(\beta=0.11, t=1.93, p<.10)$. However, when employees have low levels of LGO, more local government structural empowerment practices result in lower levels of employees' psychological empowerment, since the relationship is significant and negative $(\beta=-0.13, t=-2.27, p<.05)$.

Figure 2. Effects of structural empowerment on psychological empowerment according to LGO

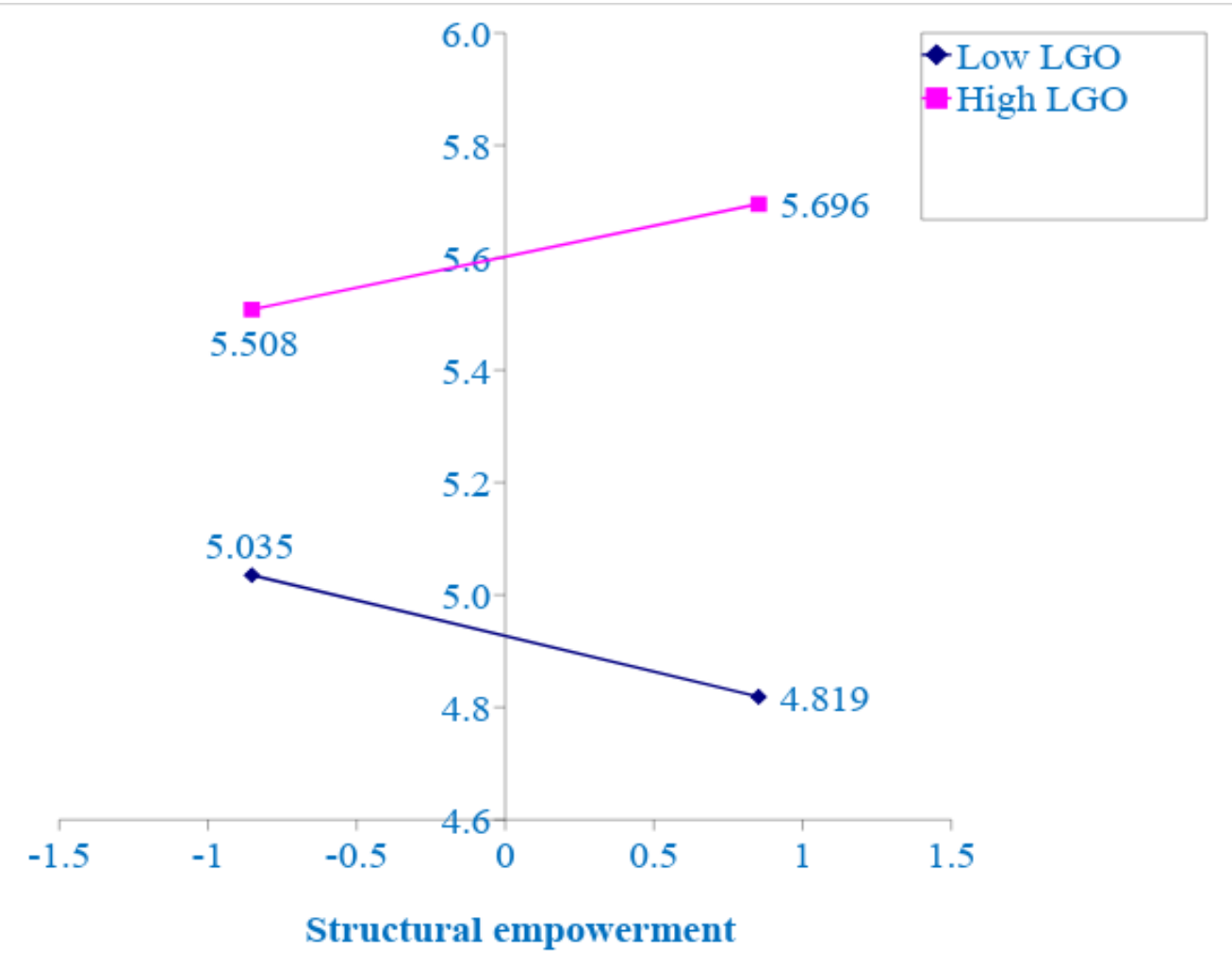




\section{Supplementary analyses}

To further examine the relationships between structural empowerment, psychological empowerment and the moderating role of GO dimensions, we repeated the hierarchical regression analysis by estimating four models, one for each of the four dimensions of structural empowerment (information, training and knowledge, rewards and decision-making power) instead of using the single index. The results show that the models with training and knowledge, and decision-making power dimensions maintain the same significant relationship as that considering the overall construct of structural empowerment; that is, the interaction of LGO and each of these two dimensions presented a significant direct influence on psychological empowerment. In contrast, by themselves the information and rewards dimensions do not show any significant link, neither a direct link nor with the interactions with each one of the GO dimensions. These findings suggest that employees' psychological empowerment levels are only fostered when LGO is combined with providing training for employees and empowering them to make decisions.

\section{DISCUSSION AND CONCLUDING REMARKS}

\section{Contribution and theoretical and practical implications}

The literature review evidences the importance of empowerment in the current human resources management field. Furthermore, given the implementation of NPM reforms in the public sector, local governments offer an illustrative context for this research because of the growing significance of empowerment. Structural empowerment practices are thought to have beneficial effects for employees, including psychological empowerment. In addition, we examined employees' goal orientations in response to calls for research on individual variables that may moderate this relationship, and on motivation issues in the public sector context. GO theory offers insights into how to link and examine the relationships among the variables of interest. 
Our findings partially support our predictions. Contrary to our expectations, the structural empowerment practices did not explain the differences in psychological empowerment levels of employees. LGO emerges as a powerful moderator of this relationship, although PPGO and APGO had no effect. A theoretical discussion of some of the specific contributions of these results now follows.

Firstly, our study did not find a significant link between structural empowerment and psychological empowerment, in contrast to previous studies (e.g., Cho and Faerman 2010; Wallace et al. 2011). There are several possible explanations for these unexpected findings. The first of these is that public sector employees may construct psychological empowerment in a different way to employees of private organizations. The intrinsic rewards that public sector employees receive from performing a task are the most important motivating factor (Houston 2000); it therefore seems that their emotional states and internal motivations are more important, and do not depend on external circumstances as much as those of private sector workers. Arguments from job crafting theory may support such reasoning. This theory holds that "employees craft their jobs by changing cognitive, task, and/or relational boundaries to shape interactions and relationships with others at work" (Wrzesniewski and Dutton 2001, 179). Public employees may create their own psychological empowerment feelings, and may be less affected by external interventions such as structural empowerment. Thus, as Nielsen (2013) states, they are the main actors involved in shaping the results of the organizational interventions. Employees, therefore, have a direct influence on how they feel about their job; they affect their own meaning, competence, impact, and states of autonomy, rather than being affected by structural empowerment initiatives. In this line of argument, previous studies on the link between employees' individual characteristics and the structure of their psychological empowerment have shown that, for example, high levels of need for achievement (Hon and Rensvold 2006) and positive self-evaluation traits (Seibert, Wang, and Courtright 2011) are 
closely associated with psychological empowerment. In sum, employees' personal features and their own dominance over their mental frameworks and feelings should not be ignored in the public sector context.

Another possible explanation for our unexpected findings on the non-significant effects of structural empowerment on psychological empowerment may be related to publication bias. Significant relationships predominate in the published literature (Sutton et al. 2000). Therefore, studies that do not support the structural-psychological empowerment relationship are less likely to be published, which may explain the prevalence of studies reporting this positive and significant link, and the lack of research showing a non-significant relationship.

Secondly, our hypotheses on the moderating variables have been partially confirmed. High levels of LGO strengthen the linkage between structural and psychological empowerment notably, such that it becomes significant and positive. Therefore, the interaction of structural empowerment interventions and high levels of personal LGO are associated with high levels of feelings of impact, significance, self-determination, and competence in public employees. In contrast, low levels of LGO have a negative effect on this link, since structural empowerment is associated with lower levels of psychological empowerment. This supports the hypothesis that the individual orientation to learn and develop serves to make structural empowerment practices effective for generating psychological empowerment feelings in employees. It helps to complement and better understand the relationship between two types of empowerment previously studied without taking into account moderating effects (e.g., Cho and Faerman 2010). By contrast, we found no significant moderation effects of PPGO or APGO in the main structural-psychological empowerment relationship. These results invite some speculation. It is possible that structural empowerment is not reinforced by performance goal orientations because of its specific components. In this study structural empowerment comprises training and knowledge, information sharing, and power to make decisions, and rewards. As stated by 
Fernandez and Moldogaziev (2013), empowerment practices have diverging effects. Perhaps training and knowledge, information sharing, and power to make decisions are not sufficient for individuals with high performance goal orientation (PPGO or APGO) to be able to demonstrate their abilities, or they may not represent situations in which employees' capabilities can be displayed, well or badly, and assessed. Rather, these practices focus more on involving, motivating and developing employees' skills. Thus, if there are no specific protocols or processes with which to assess and reward employees (apart from the bonus they receive for achieving individual or group targets that are actually private, monetary recognitions), the interaction of their willingness to demonstrate their aptitudes, be positively judged, compete against others, or avoid undesirable evaluations with the structural empowerment interventions cannot strengthen the effects of these empowerment practices. The structural-psychological empowerment link therefore remains insignificant regardless of employees' PPGO and APGO levels. Theoretically, it helps to shed more light on the moderating power of public employees' individual preferences for the structural-psychological empowerment relationship.

In addition to the theoretical contributions, this study also has some practical implications. First, the findings demonstrate that structural empowerment practices are not associated with employees' psychological empowerment. Therefore, in this context, merely putting structural empowerment practices in place is not sufficient to generate psychological empowerment in workers. This suggests that selecting employees who are able to promote their own psychological empowerment feelings is one possible way to cultivate a staff of psychologically empowered employees. Managers could also encourage this by offering employees the opportunity to shape their job according to their preferences and capabilities (Wrzesniewski and Dutton 2001), since this job crafting procedure leads to a more meaningful 
view of work (Tims and Bakker 2010; Wrzesniewski and Dutton 2001), and may ultimately help psychological empowerment feelings, regardless of management interventions.

Secondly, the results suggest the value of employees' LGO in reinforcing the power of structural empowerment interventions to generate more psychologically empowered employees. Individuals who report higher levels of these empowerment feelings in the long term are likely to perform more effectively and behave better in their organizations (Jong and Ford 2016). Thus, taking into account the NPM paradigm and its new ideas about the role of human resources and their involvement in and importance to improving services for citizens, finding a way to have more learning goal-oriented employees could help to improve service delivery. In this respect, staff selection systems should be modified to take into account employees' competence and attitudes, such as LGO, as far as legal regulations on public employee selection allow it. Public employees generally have permanent contracts with the organization (Barba and Serrano 2015). For instance, the Spanish public administration uses several different staff selection systems, but all of them involve written tests to prove the candidate has the knowledge and abilities required for the job. Psychological tests and interviews may be included, but they are rarely used. It would therefore be appropriate to routinely carry out tests to assess candidates' LGO, and thus match them with the knowledge and skills required for the job.

\section{Limitations and future directions}

The study has certain limitations, and also raises issues to address in future research. First, the data were obtained at a single point of time, so causality among the constructs cannot be assumed. A longitudinal study design could usefully assess the causal links. Another limitation is the use of self-reported and perception-based assessments. Most of the data were obtained through such sources, which are more likely to produce biased responses because of the social desirability and common method variance phenomena. Although we took data from 
two different sources and guaranteed the confidentiality of the responses, managers and employees may have over-reported desirable local government and individual characteristics, respectively. Future research should strive to mitigate this bias by introducing objective information.

\section{Conclusions}

In an attempt to go deeper into the structural and psychological empowerment link in the public sector, and the role of employees' goal orientations in this relationship, we provide empirical evidence grounded in the framework of local government. This study extends research in the field of empowerment by analyzing its dual perspective, finding an absence of any significant link between the two types, which suggests the importance of the intrinsic power of employees to generate their own feelings of empowerment. Furthermore, this study provides new empirical evidence by showing the key role LGO plays in making structural empowerment practices effective to create employees' feelings of psychological empowerment. To the best of our knowledge, our research is the first to expand understanding of the link between structural and psychological empowerment by analyzing the moderator role of goal orientations, incorporating motivation issues in this link. In sum, the findings suggest that the combination of structural empowerment practices and employees' high levels of LGO are important factors for creating psychologically empowered staff in public organizations. 


\section{APPENDIX}

\section{Structural Empowerment (Manager survey)}

Scale: 1 (no employees) to 7 (all employees).

Power to make decisions. Please indicate how many employees of your city council are currently participating in each of the following programs:

1. Survey feedback.

2. Job enrichment.

3. Quality circles.

4. Employee participation groups other than quality circles.

5. Union-management quality of work committees.

6. Self-managing work teams.

7. Employee committees on local government policy and/or strategy.

Information sharing. Please indicate how many employees of your city council are routinely provided with the following types of information:

8. Information about the local government's performance.

9. Information about their unit's performance.

10. Advance information on new technologies that may affect them.

11. Information on local government plans/goals.

12. Information on other local governments' performance.

Rewards. Please indicate how many employees of your city council are covered by each of these remuneration or reward systems:

13. Bonus for achieving individual goals

14. Bonus for achieving group goals 
Knowledge and training. Please indicate how many employees of your city council have received, in the last three years, systematic and programmed training on the following topics:

15. Group decision-making/problem-solving skills.

16. Leadership skills.

17. Skills in understanding public administration and local government.

18. Quality/statistical analysis skills.

19. Team building skills

20. Job skills training.

21. Cross-training skills other than those required for the job.

22. Skills in using information technology and computers.

\section{Psychological Empowerment (Employee survey)}

Please mark the number that represents how you feel about these questions ( 1 strongly disagree

- 7 strongly agree):

Meaning

1. The work I do is very important to me.

2. My job activities are personally meaningful to me.

3. The work I do is meaningful to me.

Competence

4. I am confident about my ability to do my job.

5. I am self-assured about my capabilities to perform my work activities.

6. I have mastered the skills necessary for my job.

Self-determination

7. I have significant autonomy in determining how I do my job.

8. I can decide on my own how to go about doing my work.

9. I have considerable opportunity for independence and freedom in how I do my job. 
Impact

10. My impact on what happens in my department is large.

11. I have a great deal of control over what happens in my department.

12. I have significant influence over what happens in my department.

\section{Goal Orientation (Employee survey)}

Please fill in the number that represents how you feel about these questions ( 1 strongly disagree - 7 strongly agree).

\section{LGO}

1. I am willing to select a challenging work assignment that I can learn a lot from.

2. I often look for opportunities to develop new skills and knowledge.

3. I enjoy challenging and difficult tasks at work where I'll learn new skills.

4. For me, development of my work ability is important enough to take risks.

5. I prefer to work in situations that require a high level of ability and talent.

\section{PPGO}

6. I like to show that I can perform better than my coworkers.

7. I try to figure out what it takes to prove my ability to others at work

8. I enjoy it when others at work are aware of how well I am doing.

9. I prefer to work on projects where I can prove my ability to others.

\section{APGO}

10. I would avoid taking on a new task of there was a chance that I would appear rather incompetent to others.

11. Avoiding a show of low ability is more important to me than learning a new skill.

12. I'm concerned about taking on a task at work if my performance would reveal that I had low ability.

13. I prefer to avoid situations at work where I might perform poorly. 


\section{REFERENCES}

Aiken, Leona S., and Stephen G. West. 1991. Multiple Regression: Testing and Interpreting Interactions. Newbury Park, CA: Sage Publications.

Ames, Carole. 1992. Classrooms: Goals, structures, and student motivation. Journal of Educational Psychology 84(3):261-271.

Bandura, Albert. 1977. Self-efficacy: toward a unifying theory of behavioral change. Psychological review 84(2):191-215.

Barba, María I., and José Serrano. 2015. Is human resource management in local councils useful? Investigaciones Europeas de Dirección y Economía de la Empresa 21:9-16.

Biron, Michal, and Peter Bamberger. 2010. The impact of structural empowerment on individual well-being and performance: Taking agent preferences, self-efficacy and operational constraints into account. Human Relations 63(2):163-191.

Bowen, David E., and Edward E. Lawler. 1992. The Empowerment of Service Workers: What, Why, How, and When. Sloan Management Review 33(3):31-39.

Bowen, David E., and Edward E. Lawler. 1995. Empowering service employees. Sloan management review 36(4):73-84.

Brett, Joan F., and Don VandeWalle. 1999. Goal Orientation and Goal Content as predictors of performance in a training program. Journal of Applied Psychology 84(6):863-873.

Brett, Joan F., and Leanne E. Atwater. 2001. 360 feedback: Accuracy, reactions, and perceptions of usefulness. Journal of Applied Psychology 86(5):930-942.

Brewer, Gene A., and J. Edward Kellough. 2016. Administrative values and public personnel management: reflections on civil service reform. Public Personnel Management 45(2):171-189. 
Buelens, Marc, and Herman Van den Broeck. 2007. An analysis of differences in work motivation between public and private sector organizations. Public administration review 67(1):65-74.

Butler, Deborah L., and Philip H. Winne. 1995. Feedback and self-regulated learning: A theoretical synthesis. Review of educational research 65(3):245-281.

Button, Scott B., John E. Mathieu, and Dennis M. Zajac. 1996. Goal orientation in organizational research: A conceptual and empirical foundation. Organizational behavior and human decision processes 67(1):26-48.

Carless, Sally A. 2004. Does Psychological Empowerment Mediate the Relationship Between Psychological Climate and Job Satisfaction? Journal of Business and Psychology 18(4):405-425.

Cellar, Douglas F., Alice F. Stuhlmacher, Samuel K. Young, David M. Fisher, Christopher K. Adair, Sarah Haynes, Emily Twichell, Kathleen A. Arnold, Kendra Royer, Bethany Lynn Denning, Devon Riester. 2011. Trait goal orientation, self-regulation, and performance: A meta-analysis. Journal of Business and Psychology 26(4):467-483.

Chadwick, Ingrid C., and Jana L. Raver. 2015. Motivating Organizations to Learn: Goal Orientation and Its Influence on Organizational Learning. Journal of Management 41(3):957-986.

Chen, Huei-Fang, and Yi-Ching Chen. 2008. The impact of work redesign and psychological empowerment on organizational commitment in a changing environment: An example from Taiwan's state-owned enterprises. Public Personnel Management 37(3):279-302.

Chen, Gilad, Stanley M. Gully, Jon-Andrew Whiteman, and Robert N. Kilcullen. 2000. Examination of relationships among trait-like individual differences, state-like individual differences, and learning performance. Journal of Applied Psychology 85(6):835-847. 
Cho, Taejun, and Sue R. Faerman. 2010. An Integrative Model of Empowerment and Individuals' In-Role and Extra Role Performance in the Korean Public Sector: Moderating Effects of Organizational Individualism and Collectivism. International Public Management Journal 13(2):130-154.

Coad, Alan F. 1999. Some survey evidence on the learning and performance orientations of management accountants. Management Accounting Research 10(2):109-135.

Collins, Christopher J., and Ken G. Smith. 2006. Knowledge exchange and combination: The role of human resource practices in the performance of high-technology firms. Academy of management journal 49(3):544-560.

Conger, Jay A., and Rabindra N. Kanungo. 1988. The empowerment process: Integrating theory and practice. Academy of Management Review 13(3):471-483.

Cuenca, Javier. 2002. La gestión estratégica de recursos humanos en las entidades locales. Capital Humano 15(161):32-38.

Cuenca, Javier. 2010. Manual de Dirección y Gestión de Recursos Humanos en los Gobiernos Locales 1st ed., Madrid: Instituto Nacional de Admón. Pública.

Datta, Deepak K., James P. Guthrie, and Patrick M. Wright. 2005. Human resource management and labor productivity: does industry matter? Academy of management Journal 48(1):135-145.

Deci, Edward L., and Richard M. Ryan. 1980. The empirical exploration of intrinsic motivational processes. In Advances in experimental social psychology, ed. L. Berkowitz, 39-80. New York: Academic.

Deci, Edward L., Richard M. Ryan, Marylène Gagné, Dean R. Leone, Julian Usunov, and Boyanka P. Kornazheva. 2001. Need satisfaction, motivation, and well-being in the work organizations of a former eastern bloc country: A cross-cultural study of selfdetermination. Personality and social psychology bulletin 27(8):930-942. 
DeShon, Richard P., and Jennifer Z. Gillespie. 2005. A motivated action theory account of goal orientation. Journal of Applied Psychology 90(6):1096-1127.

Dietz, Bart, Daan van Knippenberg, Giles Hirst, and Simon Lloyd D. Restubog. 2015. Outperforming whom? A multilevel study of performance-prove goal orientation, performance, and the moderating role of shared team identification. Journal of Applied Psychology 100(6):1811-1824.

Dillman, Don A., Jolene D. Smyth, and Leah Melani Christian. 2009. Internet, Mail and MixedMode Surveys: The Tailored Design Method. New Jersey: John Wiley \& Sons.

Dimitriades, Zoe S. 2005. Employee empowerment in the Greek context. International Journal of Manpower 26(1):80-92.

Dimitriades, Zoe. S., and Theodore Maroudas. 2007. Internal service climate and psychological empowerment among public employees. Transforming Government: People, Process and Policy 1(4):377-400.

Dweck, Carol S. 1975. The role of expectations and attributions in the alleviation of learned helplessness. Journal of personality and social psychology 31(4):674-685.

Dweck, Carol S. 1986. Motivational Processes Affecting Learning. American Psychologist, 41(10):1040-1048.

Elliot, Andrew J., and Arien C. Moller. 2003. Performance-approach goals: good or bad forms of regulation? International Journal of Educational Research 39(4-5):339-356.

Elliot, Andrew J., and Judith M. Harackiewicz. 1996. Approach and Avoidance Achievement goals and intrinsic motivation: a meditational analysis. Journal of Personality and Social Psychology 70(3):461-475.

Elliot, Andrew J., and Marcy A. Church. 1997. A hierarchical model of approach and avoidance achievement motivation. Journal of Personality and Social Psychology 72(1):218-232. 
Fernandez, Sergio, and Tima Moldogaziev. 2011. Empowering public sector employees to improve performance: does it work? The American Review of Public Administration 41(1):23-47.

Fernandez, Sergio, and Tima Moldogaziev. 2013. Using Employee Empowerment to Encourage Innovative Behavior in the Public Sector. Journal of Public Administration Research and Theory 23(1):155-187.

Fernandez, Sergio, William G. Resh, Tima Moldogaziev, and Zachary W. Oberfield. 2015. Assessing the past and promise of the Federal Employee Viewpoint Survey for public management research: A research synthesis. Public Administration Review 75(3):382394.

Gardner, Timothy M., Patrick M. Wright, and Lisa M. Moynihan. 2011. The impact of motivation, empowerment, and skill-enhancing practices on aggregate voluntary turnover: The mediating effect of collective affective commitment. Personnel psychology 64(2):315-350.

Ghauri, Pervez, Kjell Gronhaug, and Ivar Kristianslund. 1995. Research methods in business studies: a practical guide. London: Prentice Hall.

Giménez, Victor M., and Diego Prior. 2007. Long- and Short-Term Cost Efficiency Frontier Evaluation: Evidence from Spanish Local Governments. Fiscal Studies 28(1):121-139.

Gong, Yaping, Jia-Chi Huang, and Jiing-Lih Farh. 2009. Employee learning orientation, transformational leadership, and employee creativity: The mediating role of employee creative self-efficacy. Academy of Management Journal 52(4):765-778

Hempel, Paul S., Zhi-Xue Zhang, and Yulan Han. 2012. Team empowerment and the organizational context: Decentralization and the contrasting effects of formalization. Journal of Management 38(2):475-501. 
Hon, Alice HY, and Roger B. Rensvold. 2006. An interactional perspective on perceived empowerment: the role of personal needs and task context. The International Journal of Human Resource Management 17(5):959-982.

Houston, David J. 2000. Public-service motivation: A multivariate test. Journal of Public Administration Research and Theory 10(4):713-727.

Huang, T.C. 2000. Are the human resource practices of effective firms distinctly different from those of poorly performing ones? Evidence from Taiwanese enterprises. International Journal of Human Resource Management 11 (2),436-451.

Jong, Jaehee, and Michael T. Ford. 2016. The Lagged Effects of Job Demands and Resources on Organizational Commitment in Federal Government Agencies: A Multi-Level Analysis. Journal of Public Administration Research and Theory 26(3):475-492.

Joo, Baek-Kyoo, and Sunyoung Park. 2010. Career satisfaction, organizational commitment, and turnover intention: The effects of goal orientation, organizational learning culture and developmental feedback. Leadership \& Organization Development Journal 31(6):482-500.

Joo, Baek-Kyoo, Jong Gyu Park, and Taejo Lim. 2016. Structural determinants of psychological well-being for knowledge workers in South Korea. Personnel Review 45(5):1069-1086.

Kim, Soonhee, and Bradley E. Wright. 2007. IT employee work exhaustion toward an integrated model of antecedents and consequences. Review of Public Personnel Administration 27(2):147-170.

Laschinger, Heather K., Joan Finegan, and Judith Shamian. 2001. The impact of workplace empowerment and organizational trust on staff nurses' work satisfaction and organizational commitment. Health Care Management Review 26(3):7-23. 
Laschinger, Heather K., Joan Finegan, Judith Shamian and Piotr Wilk. 2004. A longitudinal analysis of the impact of workplace empowerment on work satisfaction. Journal of Organizational Behavior 5(4):527-545.

Lawler, Edward E., S. Albers Mohrman, and George Benson. 2001. Organizing for highperformance: Employee involvement, TQM, reengineering, and knowledge management in the Fortune 1000. San Francisco, CA: Jossey-Bass.

Lee, Cynthia, Catherine Tinsley, and Philip Bobko. 2003. Cross-cultural Variance in Goal Orientations and their Effects. Applied Psychology 52(2):272-297.

Martin, Andrew J., Herbert W. Marsh, and Raymond L. Debus. 2001. Self-handicapping and defensive pessimism: Exploring a model of predictors and outcomes from a selfprotection perspective. Journal of Educational Psychology 93(1)87-102.

Mathieu, John E., Lucy L. Gilson, and Thomas M. Ruddy. 2006. Empowerment and team effectiveness: an empirical test of an integrated model. Journal of applied psychology 91(1):97-108.

Matthews, Russell A., Wendy Michelle Diaz, and Steven G. Cole. 2003. The organizational empowerment scale. Personnel Review 32(3):297-318.

Maynard, M. Travis, Lucy L. Gilson, and John E. Mathieu. 2012. Empowerment - Fad or Fab? A Multilevel Review of the Past Two Decades Research. Journal of Management 38(4):1231-1281.

Menon, Sanjay. 2001. Employee empowerment: An integrative psychological approach. Applied Psychology 50(1):153-180.

Midgley, Carol, and Tim Urdan. 2001. Academic self-handicapping and achievement goals: A further examination. Contemporary educational psychology 26(1):61-75. 
Midgley, Carol, Avi Kaplan, and Michael Middleton. 2001. Performance-approach goals: Good for what, for whom, under what circumstances, and at what cost? Journal of Educational Psychology 93(1):77-86.

Nicholson-Crotty, Sean, Jill Nicholson-Crotty, and Sergio Fernandez. 2016. Performance and Management in the Public Sector: Testing a Model of Relative Risk Aversion. Public Administration Review doi:10.1111/puar.12619

Nielsen, Karina. 2013. How can we make organizational interventions work? Employees and line managers as actively crafting interventions. Human Relations 66(8):1029-1050.

Payne, Stephanie C., Satoris S. Youngcourt, and J. Matthew Beaubien, 2007. A Meta-Analytic Examination of the Goal Orientation Nomological Net. Journal of Applied Psychology 92(1):128-150.

Perry, James L. 2010. A strategic agenda for public human resource management research. Review of Public Personnel Administration 30(1):20-43.

Peters, B. Guy, and Donald J. Savoie. 1996. Managing incoherence: The coordination and empowerment conundrum. Public Administration Review 56(3):281-290.

Petter, John, Patricia Byrnes, Do-Lim Choi, Frank Fegan, and Randy Miller. 2002. Dimensions and patterns in employee empowerment: Assessing what matters to street-level bureaucrats. Journal of Public Administration Research and Theory 12(3):377-400.

Phan, Huy Phuong. 2009. Relations between goals, self-efficacy, critical thinking and deep processing strategies: a path analysis. Educational Psychology 29(7):777-799.

Pintrich, Paul R. 2000. Multiple goals, multiple pathways: The role of goal orientation in learning and achievement. Journal of Educational Psychology 92(3):544-555.

Poister, Theodore H., and Gregory Streib. 2005. Elements of Strategic Planning and Management in Municipal Government: Status after two Decades. Public Administration Review 65(1):45-56. 
Preenen, Paul, Annelies van Vianen, and Irene de Pater. 2014. Challenging tasks: The role of employees' and supervisors' goal orientations. European Journal of Work and Organizational Psychology 23(1):48-61.

Rosa, Carolina Pontones, Rosario Pérez Morote, and Clara Isabel Muñoz Colomina. 2013. Performance Improvement in the Spanish Local Government: A Proposal for Internal Control in Social Care Services. International Business Research 6(4):10-24.

Rusk, Natalie, and Fred Rothbaum. 2010. From stress to learning: Attachment theory meets goal orientation theory. Review of General Psychology 14(1):31-43.

Seibert, Scott E., Seth R. Silver, and W. Alan Randolph. 2004. Taking Empowerment to the Next Level: a Multiple-Level Model of Empowerment, Performance, and Satisfaction. Academy of Management Journal 47(3):332-349.

Seibert, Scott E., Gang Wang, and Stephen H. Courtright. 2011. Antecedents and Consequences of Psychological and Team Empowerment in Organizations: A Meta-Analytic Review. Journal of Applied Psychology 96(5):981-1003.

Siegall, Marc, and Susan Gardner. 2000. Contextual factors of psychological empowerment. Personnel Review 29(6):703-722.

Spinath, Birgit, and Ricarda Steinmayr. 2012. The roles of competence beliefs and goal orientations for change in intrinsic motivation. Journal of Educational Psychology 104(4):1135-1148.

Spreitzer, Gretchen M. 1995. Psychological empowerment in the workplace: dimensions, measurement, and validation. Academy of Management Journal 38(5):1442-1465.

Spreitzer, Gretchen M. 1996. Social structural characteristics of psychological empowerment. Academy of management journal 39(2):483-504. 
Suárez-Barraza, Manuel F., and Tamyko Ysa. 2011. An empirical study of continuous process improvement (CPI) regarding public management in Spanish municipalities. Administración \& Desarrollo 39(53):75-100.

Sutton, Alex J., Duval, S. J., Tweedie, R. L., Abrams, K. R., and Jones, D. R. 2000. Empirical assessment of effect of publication bias on meta-analyses. Bmj 320(7249):1574-1577.

Taylor, Jeannette. 2013. Goal setting in the Australian public service: Effects on psychological empowerment and organizational citizenship behavior. Public Administration Review 73(3):453-464.

Thomas, Kenneth W., and Betty A. Velthouse. 1990. Cognitive Elements of Empowerment an Interpretive Model of Intrinsic Task Motivation. Academy of Management Review 15(4):666-681.

Tims, Maria, and Arnold B. Bakker. 2010. Job crafting: Towards a new model of individual job redesign. South African Journal of Industrial Psychology 36(2):1-9.

Towler, Annette J., and Robert L. Dipboye. 2001. Effects of trainer expressiveness, organization, and trainee goal orientation on training outcomes. Journal of Applied Psychology 86(4):664-673.

Truss, Catherine. 2013. The distinctiveness of human resource management in the public sector. In Human Resource Management in the Public Sector, ed. Ronald J. Burke, Andrew J. Noblet and Cary L. Cooper, 17-36. Cheltenham, UK; Nothampton, MA: Edward Elgar.

Üstüner, Yilmaz, and Selim Coşkun. 2004. Quality management in the Turkish public sector: a survey. Public administration and development 24(2):157-171.

Vandenabeele, Wouter, Roger Depré, Annie Hondeghem, and Shufeng Yan. 2005. The motivational patterns of civil servants. Viesoji politika ir administravimas 13:52-63. 
Vandenabeele, Wouter. 2013. Motivation, job satisfaction and retention/turnover in the public sector. In Human Resource Management in the Public Sector, ed. Ronald J. Burke, Andrew J. Noblet and Cary L. Cooper, 214-235. Cheltenham, UK; Nothampton, MA: Edward Elgar.

VandeWalle, Don. 1997. Development and Validation of a work domain goal orientation instrument. Educational and Psychological Measurement 57(6):995-1015.

VandeWalle, Don. 2001. Goal orientation: Why wanting to look successful doesn't always lead to success. Organizational Dynamics 30(2):162-171.

VandeWalle, Don, Steven P. Brown, William L. Cron, and John W. Slocum, Jr. 1999. The influence of goal orientation and self-regulation tactics on sales performance: A longitudinal field test. Journal of Applied Psychology 84(2):249-259.

Vermeeren, Brenda, Ben Kuipers, and Bram Steijn. 2011. Two faces of the satisfaction mirror: a study of work environment, job satisfaction, and customer satisfaction in Dutch municipalities. Review of public personnel administration 31(2):171-189.

Wallace, J. Craig, Paul D. Johnson, Kimberly Mathe, and Jeff Paul. 2011. Structural and Psychological Empowerment Climates, Performance, and the Moderating Role of Shared Felt Accountability: A Managerial Perspective. Journal of Applied Psychology 96(4):840-850.

Whitehead, John C., Peter Groothuis, and Glenn Blomquist. 1993. Testing for non-response and sample selection bias in contingent valuation: Analysis of a combination phone/mail survey. Economics Letters 41(2):215-220.

Wooldridge, Jeffrey M. 2010. Introductory econometrics: A modern approach. Cincinnati: South-Western College Pub. 
Worthington, Andrew C., and Brian E. Dollery. 2001. Measuring efficiency in local government: an analysis of New South Wales municipalities' domestic waste management function. Policy Studies Journal 29(2):232-249.

Wolters, Christopher A. 2003. Understanding procrastination from a self-regulated learning perspective. Journal of Educational Psychology 95(1):179-187.

Wright, Bradley E. 2001. Public-sector work motivation: A review of the current literature and a revised conceptual model. Journal of public administration research and theory 11(4):559-586.

Wright, Bradley E. 2007. Public service and motivation: Does mission matter? Public administration review 67(1): 54-64.

Wrzesniewski, Amy, and Jane E. Dutton. 2001. Crafting a job: Revisioning employees as active crafters of their work. Academy of management review 26(2):179-201. 